\title{
FORMULATION AND CHARACTERIZATION OF MODIFIED RELEASE TABLETS CONTAINING ISONIAZID USING SWELLABLE POLYMERS
}

\author{
${ }^{1}$ M. F. Akhtar, ${ }^{1}$ M. Rabbani, ${ }^{1}$ A. Sharif, ${ }^{1}$ B. Akhtar, ${ }^{1}$ A. Saleem, ${ }^{2}$ G. Murtaza*, \\ ${ }^{1}$ Faculty of Pharmacy, Bahauddin Zakariya University, Multan, Pakistan. \\ ${ }^{2}$ Department of Pharmaceutical Sciences, COMSATS Institute of Information Technology, \\ Abbottabad, Pakistan. \\ *Email: gmdogar356@gmail.com
}

\begin{abstract}
The aim of this work was to develop swellable modified release (MR) isoniazid tablets using different combinations of polyvinyl acetate (PVAc) and sodium-carboxymethylcellulose (Na-CMC). Granules were prepared by moist granulation technique and then compressed into tablets. In vitro release studies for $12 \mathrm{hr}$ were carried out in dissolution media of varying $\mathrm{pH}$ i.e. $\mathrm{pH} 1.2,4.5,7.0$ and 7.5. Tablets of all formulations were found to be of good physical quality with respect to appearance (width and thickness), content uniformity, hardness, weight variation and friability. In vitro release data showed that increasing total polymer content resulted in more retarding effect. Formulation with $35 \%$ polymer content exhibited zero order release profile and it released $35 \%$ of the drug in first hr, later on, controlled drug release was observed upto the $12^{\text {th }}$ hour. Formulations with PVAc to Na-CMC ratio 20:80 exhibited zero order release pattern at levels of studied concentrations, which suggested that this combination can be used to formulate zero order release tablets of water soluble drugs like isoniazid. Korsmeyer-Peppas modeling of drug release showed that non-Fickian transport is the primary mechanism of isoniazid release from PVAc and Na-CMC based tablets. The value of mean dissolution time decreased with the increase in the release rate of drug clearly showing the retarding behavior of the swellable polymers. The application of a mixture of PVAc to Na-CMC in a specific ratio may be feasible to formulate zero order release tablets of water soluble drugs like isoniazid.
\end{abstract}

Keywords: Isoniazid, Polyvinyl acetate, Sodium-carboxymethylcellulose, Modified release tablets.

\section{Introduction}

Tuberculosis is a rampant infectious disease and is considered to be the foremost cause of death from a single microorganism. Annually worldwide, of the 8 million people who actively manifest the disease, 3 million die (Hara and Hickey, 2002). Tuberculosis (TB) has been declared a public health emergency by the World Health Organization (WHO). Isoniazid, rifampicin, pyrizinamide and ethambutol were earlier prescribed as separate formulations in TB control. WHO and International Union against Tuberculosis and Lung Disease recommend the use of fixed dose combination formulations of the essential anti-tuberculosis drugs to ensure adequate treatment of patients (Blomberg et al. 2001). Isoniazid is the most prescribed drug for the treatment and prophylaxis of tuberculosis. It is a highly water soluble drug and have a pKa of 7-7.5. Its bioavailability through out the intestinal tract proves it to be a strong candidate for sustained drug delivery (Mariappan and Singh, 2003).

Swellable polymers have gained wide interest recently for formulation of controlled release tablets because of their non-toxic and erodible nature. Swellable polymers offer the advantage of initial high release which eliminates the requirement of separate loading doses. Na-CMC has been widely investigated for its drug release retarding capabilities which forms gel when hydrated and later on dissolves in dissolution media. PVAc is a water insoluble swellable polymer which has only been investigated alone and in combination with PVP in the form of Kollidon ${ }^{\mathbb{B}}$ SR (Reza et al. 2003) in formulating controlled release tablets. These findings offer a potential combination of $\mathrm{Na}-\mathrm{CMC}$ and PVAc to be investigated for drug release retarding properties.

Varying $\mathrm{pH}$ conditions throughout the gastrointestinal tract is an important factor influencing the drug release from the dosage form. This leads to affect the absorption of drug from the gastrointestinal tract. It is therefore necessary to study drug release at varying $\mathrm{pH}$ conditions. The British Pharmacopoeia 2007 (BP, 2007) gives insight into the various $\mathrm{pH}$ conditions at which the dissolution procedure should be conducted. Therefore, dissolution studies were conducted at varying $\mathrm{pH}$ conditions in this study.

In present study, a model of sustained release design has been implemented. The proposed formulation would also be useful for an individual having half life of isoniazid about $1 \mathrm{~h}$ and the desired concentration will be maintained. In fast acetylator persons as isoniazid is excreted through acetylation process in the liver. By this technique, a dosage form was formulated which would be released for about $12 \mathrm{~h}$ at almost constant drug level much above the MEC. In present study, different concentrations of single polymer and ratios of polymers i.e. PVAc and Na-CMC were used to prepare modified release swellable isoniazid tablets that were formed by moist granulation technique and compressed into tablets. These tablets were then evaluated in vitro by employing usual quality control tests specially the dissolution in different simulated media. 


\section{Materials and Methods Materials}

Isoniazid was a gift sample from Schazoo laboratories, Lahore, Pakistan. Polyvinyl acetate (PVAc) and sodiumcarboxymethylcellulose (Na-CMC) were purchased from Fluka, Germany. Avicel 101 was obtained from Merck, Germany. All other analytical grade chemicals i.e. potassium dihydrogen phosphate, sodium hydroxide, hydrochloric acid, magnesium stearate and talc were purchased from Merck, Germany. All the materials were used as such without further processing.

\section{Preparation of modified release swellable isoniazid tablets}

Twelve different formulations were prepared using wet granulation method. The composition of formulations are shown in Table 1. All ingredients were accurately weighed. Isoniazid, PVAc, Na-CMC and Avicel were mixed together for 10 minutes in the pestle and mortar. Wet mass was prepared using water in a small quantity as a moistening agent for adhering the powder particles. The moist mass was then pressed through a screen (Mesh size 8) and granules were dried in a thermostatically controlled oven at $45{ }^{\circ} \mathrm{C}$ for $2 \mathrm{~h}$. The granules were again passed through a screen (Mesh size 18). Magnesium stearate and talc were added to improve flow of granules from hopper to die cavity and to prevent adhesion of granules to punches. Then the granules were compressed using single punch tablet machine with oblong shaped concave punches with an average weight of each tablet $550 \mathrm{mg}$. Each formulation batch consisted of about 500 tablets. Drug content for each tablet was $300 \mathrm{mg}$ per tablet. Total polymer concentrations used for preparation of swellable modified release tablets were $20 \%, 25 \%, 30 \%$ and $35 \%$. The ratio of polymers at these concentrations and the composition of different ingredients per tablet in each formulation are given in Table 1 and 2, respectively.

\section{Physical evaluation of formulations}

The flow characteristics (angle of repose) of formulated granules, weight variation, hardness, friability and dimensional measurements of prepared tablets were measured as presented by Murtaza et al. (2009) and directed in USP30NF25 (2007).

\section{Drug contents determination}

Official method of BP was used to determine the INH contents of MR INH Swellable tablets. The 20 tablets from each formulation of swellable MR isoniazid tablets were taken and crushed. Quantity of crushed material equivalent to 100 $\mathrm{mg}$ Isoniazid was taken and dissolved in $50 \mathrm{ml}$ distilled water by stirring for $10 \mathrm{~min}$. Then the volume was made up to 1000 $\mathrm{ml}$ with distilled water. Now this solution was filtered. The $2 \mathrm{ml}$ solution was taken and diluted to $20 \mathrm{ml}$ with distilled water. This sample was analyzed spectrophotometrically at a $\lambda_{\max } 263 \mathrm{~nm}$ and concentration was determined from the calibration curve.

\section{Preparation of calibration curves}

Isoniazid $100 \mathrm{mg}$ was added to $50 \mathrm{ml}$ distilled water, mixed with continuous stirring and placed in a sonicator so that the drug may completely dissolve. Then adequate volume of distilled water was added to make final volume to $1000 \mathrm{ml}$ with strength of $100 \mu \mathrm{g} / \mathrm{ml}$. This stock solution was further diluted to get $3,9,15,21,27,33$ and $39 \mu \mathrm{g} / \mathrm{ml} \mathrm{samples}$. The samples were analyzed at $263 \mathrm{~nm}$ using UV-VIS spectrophotometer (Schimadzu, Japan) and a standard curve was constructed as shown in Figure 1. The values of linearity are: slope $=0.03$, Intercept $=0.1367$ and coefficient of determination $\left(\mathrm{R}^{2}\right)=0.9971$. Since there was significant variation in $\mathrm{pH}$ conditions during dissolution procedure and isoniazid, being weekly basic drug, gives different solubilities at different $\mathrm{pH}$ solutions, therefore it was necessary to make separate calibration curves for each of these $\mathrm{pH}$ variations for accurate determinations of isoniazid contents at a specific $\mathrm{pH}$ condition (Davidson, 2002). Above mentioned procedure was repeated for the preparation of calibration curve in $\mathrm{HCl}$ buffer of $\mathrm{pH} 1.2, \mathrm{pH} 4.5, \mathrm{pH} 7.0$ and $\mathrm{pH} 7.5$ phosphate buffer solutions. The values of linearity are given below: In HCl buffer of pH 1.2, Slope $=0.0297$, Intercept $=0.1531$ and $\mathrm{R}^{2}=0.9975$.

In $\mathrm{pH} 4.5$ phosphate buffer solution, Slope $=0.0299$, Intercept $=0.1447$ and $\mathrm{R}^{2}=0.9976$.

In $\mathrm{pH} 7.0$ phosphate buffer solution, Slope $=0.0299$, Intercept $=0.14$ and $\mathrm{R}^{2}=0.9975$. In pH 7.5 phosphate buffer solution, Slope $=0.03$, Intercept $=0.1369$ and $\mathrm{R}^{2}=0.9968$.

\section{Dissolution study}

All the solutions and buffers were prepared according to BP and United States Pharmacopoeia 2007 for preparation of calibration curve of drug, dissolution and swelling study of the prepared tablets. Dissolution was carried out in apparatus II according to "Modified Half Change Method" of BP to study the release of isoniazid at different $\mathrm{pH}$ which simulates the $\mathrm{pH}$ of almost entire GIT. The temperature and stirring of medium was kept constant at $37^{\circ} \mathrm{C} \pm 0.5{ }^{\circ} \mathrm{C}$ and $50 \mathrm{rpm}$, respectively. The study was conducted for first $2 \mathrm{~h}$ in $\mathrm{HCl}$ buffer $\mathrm{pH} 1.2$, then half of this was replaced with phosphate buffer $\mathrm{pH} 7.5$ to attain $\mathrm{pH}$ 4.5. Then after $1.5 \mathrm{~h}$, half of the medium was replaced with phosphate buffer $\mathrm{pH} 7.5$ and $\mathrm{pH}$ was adjusted to 7.0. After $2 \mathrm{~h}$, half of the medium was again replaced with phosphate buffer $\mathrm{pH} 7.5$. All $\mathrm{pH}$ adjustments were carried out with 2 $\mathrm{M} \mathrm{HCl}$ and $2 \mathrm{M} \mathrm{NaOH}$ solutions (BP, 2007). The sampling time points were $0.5,1,2,3,4,5,6,7,8,9,10,11$ and $12 \mathrm{~h}$. Each time, $2 \mathrm{ml}$ of the sample was withdrawn, further diluting it to $20 \mathrm{ml}$ and analyzed by spectrophotometer. Each time sample 
withdrawn was replaced by fresh dissolution medium and $\mathrm{pH}$ was rechecked. Dissolution of each formulation was done as triplicate and then mean of these values were taken.

\section{Kinetic and mechanistic analysis of drug release pattern}

The kinetic and mechanistic analysis of drug release pattern was evaluated using various model dependent (zero and first models, Higuchi, Hixson-Crowell, Korsmeyer-Peppas Models) and independent (mean dissolution time determination) approaches as mentioned previously (Murtaza et al. 2009).

\section{Swelling studies of tablets}

Swelling studies of tablets were conducted at room temperature at five different $\mathrm{pH}$ conditions. Four studies were conducted separately at constant $\mathrm{pH}$ values of $1.2,4.5,7.0$ and 7.5. One study was conducted at varying $\mathrm{pH}$ conditions similar to those as the dissolution studies. Tablet weight was determined after zero hours, 1, 2, 3, 3.5, 4, 5, 5.5 and $6 \mathrm{~h}$. For weight measurement of tablet, it was put out of the petri dish, blotted with the tissue paper each time to remove solvent present on its surface and was then weighed and placed in its buffer again. Each experiment was repeated five times and average weight gain in the form of percentage swelling by the tablets for each formulation at different $\mathrm{pH}$ conditions were plotted against time (USP30-NF25, 2007).

Swelling Index (S.I.) or percentage swelling was calculated by the following formula S.I. $=\left\{\left(\mathrm{W}_{\mathrm{w}}-\mathrm{W}_{\mathrm{d}}\right) / \mathrm{W}_{\mathrm{d}}\right\} \times 100$

Where $\mathrm{W}_{\mathrm{w}}$ is the wet weight and $\mathrm{W}_{\mathrm{d}}$ is the dry weight of the tablet at zero time of swelling.

Table 1: Formulations of swellable modified release isoniazid tablets

\begin{tabular}{|l|c|c|c|c|c|c|c|c|}
\hline Formulation & \multicolumn{2}{|c|}{ A } & \multicolumn{2}{c|}{ B } & \multicolumn{2}{c|}{ C } & \multicolumn{2}{c|}{ D } \\
\hline $\begin{array}{l}\text { Total Polymer } \\
\text { Contents }\end{array}$ & \multicolumn{2}{|c|}{$20 \%$} & \multicolumn{2}{|c|}{$25 \%$} & \multicolumn{2}{c|}{$30 \%$} & \multicolumn{2}{c|}{$35 \%$} \\
\hline $\begin{array}{l}\text { PVAc to CMC } \\
\text { ratios }\end{array}$ & & PVAc:CMC & & PVAc:CMC & & PVAc:CMC & & PVAc:CMC \\
\cline { 2 - 9 } & A1 & $80: 20$ & B1 & $80: 20$ & C1 & $80: 20$ & D1 & $80: 20$ \\
& A2 & $50: 50$ & B2 & $50: 50$ & C2 & $50: 50$ & D2 & $50: 50$ \\
\cline { 2 - 10 } & A3 & $20: 80$ & B3 & $20: 80$ & C3 & $20: 80$ & D3 & $20: 80$ \\
\hline
\end{tabular}

Table 2: Composition of formulations of swellable modified release isoniazid tablets

\begin{tabular}{|c|c|c|c|c|c|c|c|}
\hline $\begin{array}{l}\text { Formulation } \\
\text { code }\end{array}$ & $\begin{array}{l}\text { Isoniazid } \\
(\mathrm{mg})\end{array}$ & $\begin{array}{l}\text { PVAc } \\
(\mathrm{mg})\end{array}$ & $\begin{array}{l}\text { Na-CMC } \\
(\mathrm{mg})\end{array}$ & $\begin{array}{l}\text { Avicel } \\
(\mathrm{mg})\end{array}$ & $\begin{array}{l}\text { Magnesium } \\
\text { Stearate }(\mathrm{mg})\end{array}$ & $\begin{array}{l}\text { Talc } \\
(\mathrm{mg})\end{array}$ & $\begin{array}{l}\text { Quantity per } \\
\text { Tablet }(\mathrm{mg})\end{array}$ \\
\hline A1 & 300 & 88 & 22 & 112.5 & 18.52 & 8.24 & 550 \\
\hline A2 & 300 & 55 & 55 & 112.5 & 18.52 & 8.24 & 550 \\
\hline A3 & 300 & 22 & 88 & 112.5 & 18.52 & 8.24 & 550 \\
\hline B1 & 300 & 110 & 27.5 & 90 & 18.52 & 8.24 & 550 \\
\hline B2 & 300 & 68.75 & 68.75 & 90 & 18.52 & 8.24 & 550 \\
\hline B3 & 300 & 27.5 & 110 & 90 & 18.52 & 8.24 & 550 \\
\hline C1 & 300 & 132 & 33 & 57.5 & 18.52 & 8.24 & 550 \\
\hline C2 & 300 & 82.5 & 82.5 & 57.5 & 18.52 & 8.24 & 550 \\
\hline C3 & 300 & 33 & 132 & 57.5 & 18.52 & 8.24 & 550 \\
\hline D1 & 300 & 154 & 38.5 & 30 & 18.52 & 8.24 & 550 \\
\hline D2 & 300 & 96.25 & 96.25 & 30 & 18.52 & 8.24 & 550 \\
\hline D3 & 300 & 38.5 & 154 & 30 & 18.52 & 8.24 & 550 \\
\hline
\end{tabular}

\section{Results and Discussion}

Physical evaluation of formulations

The values of angle of repose of the granules for all formulations showed good flow properties (acceptable angle of repose). Tablets of all the formulations showed satisfactory hardness and friability less than $1 \%$ which is in accordance to the limit specified by BP. All the formulations showed weight variation within limit of $5 \%$ and none of the tablets deviated more than $5 \%$ as specified by BP (Table 3 ). While the thickness and width of all tablets is given in Table 4 . The drug content assay of all the formulations were within range as specified in BP and the assay results are given in following Table 4. 
Table 3: Angle of repose of granules for all formulations

\begin{tabular}{|l|l|l|l|l|}
\hline \multirow{2}{*}{$\begin{array}{l}\text { Formu- } \\
\text { lation } \\
\text { code }\end{array}$} & $\begin{array}{c}|c| \\
\text { Angle of } \\
\text { repose }\left({ }^{\circ}\right)\end{array}$ & \multicolumn{1}{|c|}{ Hardness $(\mathrm{N})$} & \multicolumn{1}{|c|}{ Friability $(\%)$} & Weight variation test \\
\cline { 2 - 5 } & \multicolumn{1}{|c|}{ Mean \pm S.D. } & Mean \pm S.D. & Mean \pm S.D. & Mean weight (mg) \pm S.D. \\
\hline A1 & $22.76 \pm 0.25$ & $0.118 \pm 0.391$ & $0.118 \pm 0.06$ & $550.03 \pm 1.51$ \\
\hline A2 & $23.53 \pm 1.28$ & $0.126 \pm 0.275$ & $0.126 \pm 0.05$ & $550.17 \pm 1.50$ \\
\hline A3 & $23.67 \pm 0.76$ & $0.107 \pm 0.993$ & $0.107 \pm 0.08$ & $550.24 \pm 1.45$ \\
\hline B2 & $23.16 \pm 0.76$ & $0.139 \pm 0.906$ & $0.139 \pm 0.02$ & $550.33 \pm 1.72$ \\
\hline B3 & $22.83 \pm 0.28$ & $0.208 \pm 0.110$ & $0.208 \pm 0.03$ & $550.06 \pm 2.04$ \\
\hline C1 & $29.50 \pm 0.50$ & $0.239 \pm 0.894$ & $0.239 \pm 0.00$ & $550.32 \pm 1.99$ \\
\hline C2 & $25.50 \pm 0.50$ & $0.213 \pm 0.043$ & $0.213 \pm 0.08$ & $550.41 \pm 1.70$ \\
\hline C3 & $26.63 \pm 0.75$ & $0.217 \pm 0.819$ & $0.217 \pm 0.08$ & $550.23 \pm 1.89$ \\
\hline D1 & $25.90 \pm 0.40$ & $0.205 \pm 0.978$ & $0.205 \pm 0.01$ & $550.43 \pm 1.66$ \\
\hline D2 & $22.90 \pm 0.51$ & $0.189 \pm 0.013$ & $0.189 \pm 0.05$ & $549.91 \pm 1.40$ \\
\hline D3 & $25.63 \pm 0.55$ & $0.217 \pm 0.731$ & $0.217 \pm 0.09$ & $550.36 \pm 1.88$ \\
\hline
\end{tabular}

Table 4: Thickness, width and assay for all tablets

\begin{tabular}{|c|c|c|c|}
\hline \multirow{2}{*}{ Formulation code } & Thickness $(\mathrm{mm})$ & Width $(\mathrm{mm})$ & Assay (mg) \\
\cline { 2 - 4 } & Mean \pm S.D. & Mean \pm S.D. & Mean \pm S.D. \\
\hline A1 & $5.495 \pm 0.08$ & $8.1 \pm 0.05$ & $300.17 \pm 0.47$ \\
\hline A2 & $5.49 \pm 0.02$ & $8.1 \pm 0.04$ & $300.13 \pm 0.43$ \\
\hline A3 & $5.49 \pm 0.03$ & $8.1 \pm 0.06$ & $300.11 \pm 0.65$ \\
\hline B1 & $5.48 \pm 0.03$ & $8.1 \pm 0.05$ & $300.08 \pm 0.38$ \\
\hline B2 & $5.49 \pm 0.04$ & $8.1 \pm 0.04$ & $300.01 \pm 0.98$ \\
\hline B3 & $5.5 \pm 0.04$ & $8.1 \pm 0.01$ & $300.17 \pm 1.08$ \\
\hline C1 & $5.5 \pm 0.05$ & $8.1 \pm 0.02$ & $300.1 \pm 0.26$ \\
\hline C2 & $5.49 \pm 0.03$ & $8.1 \pm 0.03$ & $300.07 \pm 0.25$ \\
\hline C3 & $5.49 \pm 0.02$ & $8.1 \pm 0.04$ & $300.17 \pm 0.50$ \\
\hline D1 & $5.48 \pm 0.04$ & $8.1 \pm 0.02$ & $299.95 \pm 0.76$ \\
\hline D2 & $5.48 \pm 0.03$ & $8.1 \pm 0.05$ & $300.12 \pm 0.66$ \\
\hline D3 & $5.49 \pm 0.02$ & $8.1 \pm 0.05$ & $299.88 \pm 0.65$ \\
\hline
\end{tabular}

All the preparations i.e. A1, A2, A3, B1, B2, B3, C1, C2, C3, C4, D1, D2 and D3 were subjected to dissolution at varying $\mathrm{pH}$ and the results were obtained. The results elaborated that the combination of polymers as well as concentration of the polymers in the tablets both influenced release of water soluble drug from the tablets.

Total polymer content of $20 \%$ of the tablet was evaluated for drug release at three levels i.e. polymer ratios of 80:20, 50:50 and 20:80 of PVAc and Na-CMC in the form of A1, A2 and A3. The A1 and A2 showed initial burst release and $100 \%$ drug was released in $8 \mathrm{~h}$ where as from A3, 100\% of the drug was released in $9 \mathrm{~h}$. MDT values of A1, A2 and A3 were found to be 2.22, 2.29 and $3.44 \mathrm{~h}$, which showed that A3 had more release retarding efficacy. Release profiles are expressed in Figure 1. This initial burst release, in case of A1 and A2 might be attributed to higher PVAc to Na-CMC ratio which could not retard release of drug at lower level of Na-CMC. The A3 did not show such burst release which may be due to higher ratio of $\mathrm{Na}-\mathrm{CMC}$ which formed gel and thus retarded drug release more than $\mathrm{A} 1$ and $\mathrm{A} 2$. The PVAc was present in higher amount only in A1, which caused initial burst release due to high swelling at lower $\mathrm{pH}$. Other contributing factor for initial high release was slightly basic nature of isoniazid which dissolved more readily in acidic media, but this factor is of less importance owing to highly soluble nature of isoniazid in water.

Total polymer content of $25 \%$ of the tablet was evaluated for drug release at three levels i.e. polymer ratios of $80: 20,50: 50$ and 20:80 of PVAc and Na-CMC in the form of B1, B2 and B3. All the three formulations released 100\% drug in $9 \mathrm{~h}$. MDT values of B1, B2 and B3 were found to be 3.01, 3.09 and $3.45 \mathrm{~h}$, which showed that B3 had more release 
Table 5: Kinetic analysis of dissolution data using various models on the basis of coefficient of determination

\begin{tabular}{|c|c|c|c|c|c|c|c|}
\hline \multirow{2}{*}{$\begin{array}{l}\text { Formulation } \\
\text { code }\end{array}$} & \multirow[t]{2}{*}{ MDT } & \multirow{2}{*}{$\begin{array}{c}\text { Zero order kinetics } \\
\mathrm{R}^{2}\end{array}$} & \multirow{2}{*}{$\begin{array}{c}\text { First order } \\
\text { kinetics } \\
\mathrm{R}^{2}\end{array}$} & \multirow{2}{*}{$\begin{array}{l}\text { Higuchi } \\
\text { Model } \\
\mathrm{R}^{2}\end{array}$} & \multirow{2}{*}{$\begin{array}{c}\text { Hixson Crowell Model } \\
\mathrm{R}^{2}\end{array}$} & \multicolumn{2}{|c|}{$\begin{array}{c}\text { Korsmeyer- Peppas } \\
\text { Model }\end{array}$} \\
\hline & & & & & & $\mathrm{R}^{2}$ & $\mathrm{~N}$ \\
\hline A1 & 2.2290 & 0.8474 & 0.8264 & 0.9393 & 0.9600 & 0.9220 & 0.5063 \\
\hline A2 & 2.2998 & 0.8415 & 0.7411 & 0.9283 & 0.9130 & 0.9069 & 0.4873 \\
\hline A3 & 3.4482 & 0.9682 & 0.6972 & 0.9688 & 0.9023 & 0.9569 & 0.572 \\
\hline B1 & 3.0138 & 0.9188 & 0.7893 & 0.9699 & 0.9184 & 0.9642 & 0.5557 \\
\hline B2 & 3.0954 & 0.9692 & 0.7626 & 0.9757 & 0.9137 & 0.9708 & 0.4847 \\
\hline B3 & 3.4586 & 0.9853 & 0.7399 & 0.9742 & 0.9177 & 0.9659 & 0.525 \\
\hline $\mathrm{C} 1$ & 3.2174 & 0.8778 & 0.7102 & 0.9558 & 0.901 & 0.9308 & 0.5628 \\
\hline $\mathrm{C} 2$ & 3.7736 & 0.9745 & 0.6864 & 0.9783 & 0.8961 & 0.9596 & 0.5375 \\
\hline $\mathrm{C} 3$ & 3.5099 & 0.9004 & 0.871 & 0.9518 & 0.9751 & 0.9494 & 0.5495 \\
\hline D1 & 3.3605 & 0.805 & 0.7457 & 0.9135 & 0.9102 & 0.9105 & 0.5954 \\
\hline D2 & 4.0836 & 0.8669 & 0.981 & 0.9576 & 0.9714 & 0.8925 & 0.5961 \\
\hline D3 & 3.8859 & 0.9525 & 0.9449 & 0.9912 & 0.9489 & 0.9684 & 0.5141 \\
\hline
\end{tabular}

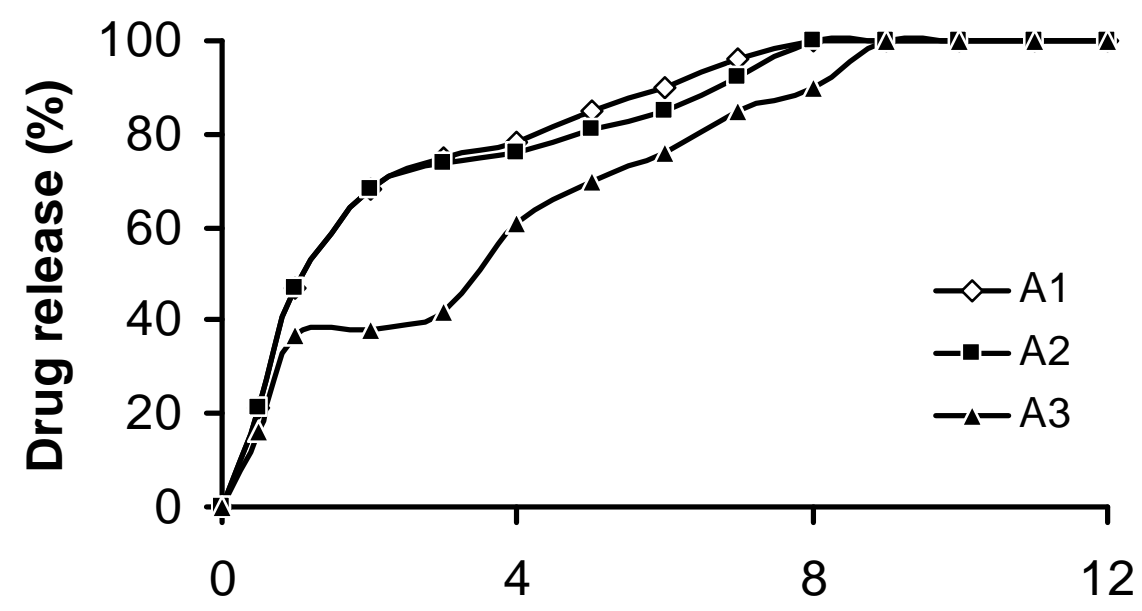

Time (h)

Figure 1: The effect of increased ratio of Na-CMC to PVAc with a constant amount of total polymer on dissolution profiles of different MR formulations A1, A2, A3.

retarding efficacy. Release profiles are expressed in Figure 2. This initial burst release, in the case of B1 and B2 may be attributed to higher level of PVAc which could not retard release of drug at low presence of Na-CMC. B3 did not show such burst release which might be due to higher ratio of $\mathrm{Na}-\mathrm{CMC}$ which formed gel and thus retarded drug release more than $\mathrm{B} 1$ and B2. PVAc was present in higher amounts in B1 and B2 than in B3, which caused initial burst release due to high swelling at lower $\mathrm{pH}$. Other contributing factor for initial high release was slightly basic nature of isoniazid which dissolved more readily in acidic media, but this factor is less important value owing to highly soluble nature of Isoniazid in water. Since Na$\mathrm{CMC}$ swelled latter on after increase in $\mathrm{pH}$, therefore it led to the increase in drug release rate after an initial $2 \mathrm{~h}$ period and caused the tablets of B3 to completely release the drug in $9 \mathrm{~h}$. 


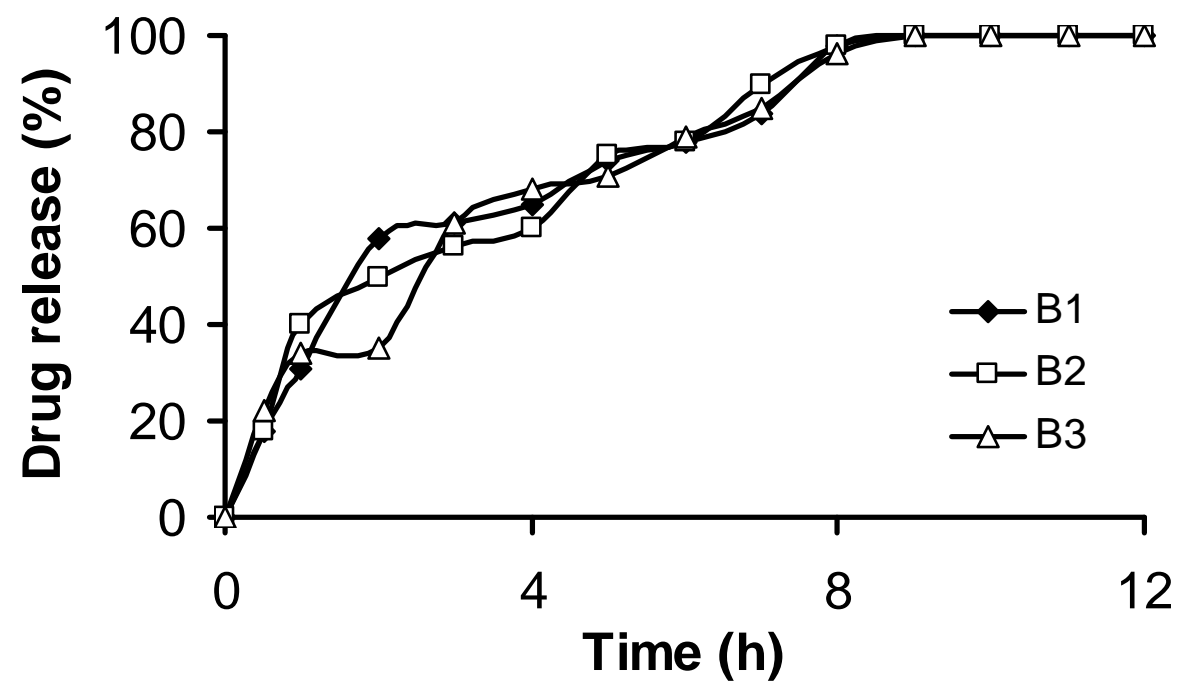

Figure 2: Influence of increased ratio of $\mathrm{Na}-\mathrm{CMC}$ to PVAc with a constant amount of total polymer on dissolution profiles of different MR formulations B1, B2 and B3.

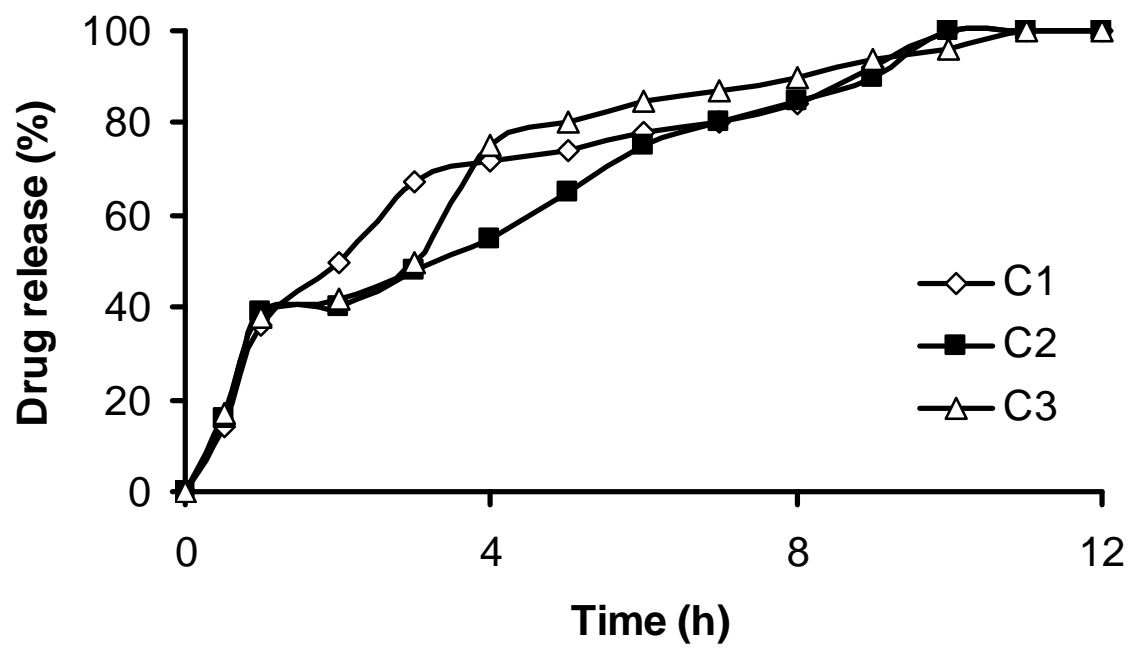

Figure 3: Influence of increased ratio of Na-CMC to PVAc with a constant amount of total polymer on dissolution profiles of different MR formulations $\mathrm{C} 1, \mathrm{C} 2$ and $\mathrm{C} 3$. 


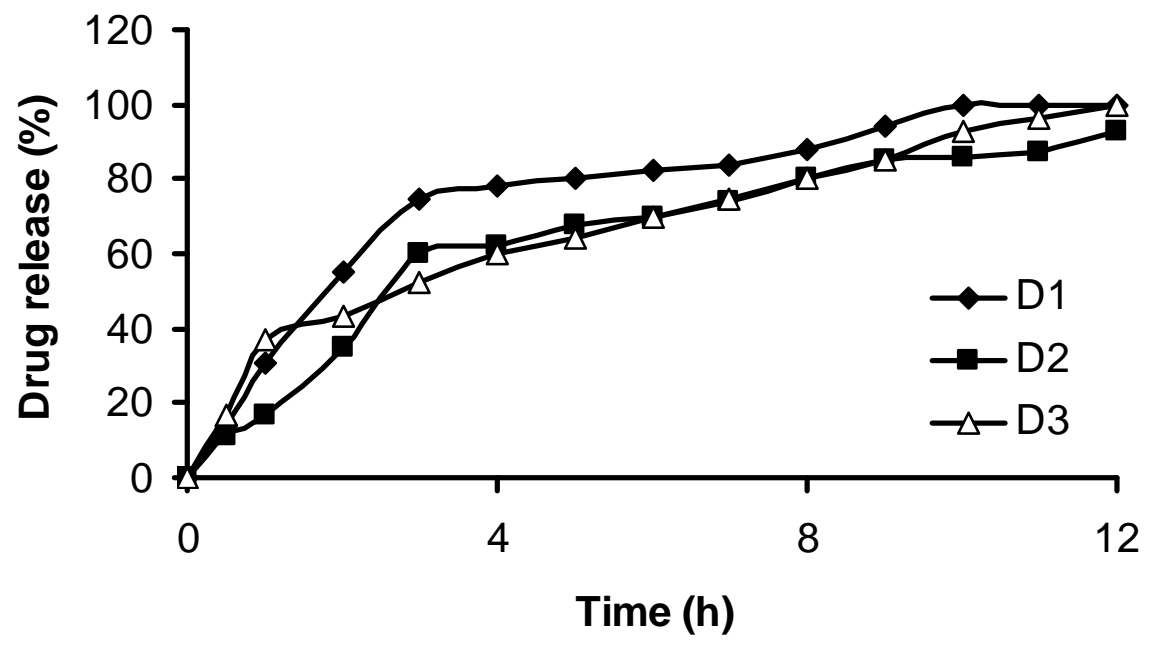

Figure 4: Influence of increased ratio of Na-CMC to PVAc with a constant amount of total polymer on dissolution profiles of different MR formulations D1, D2 and D3.

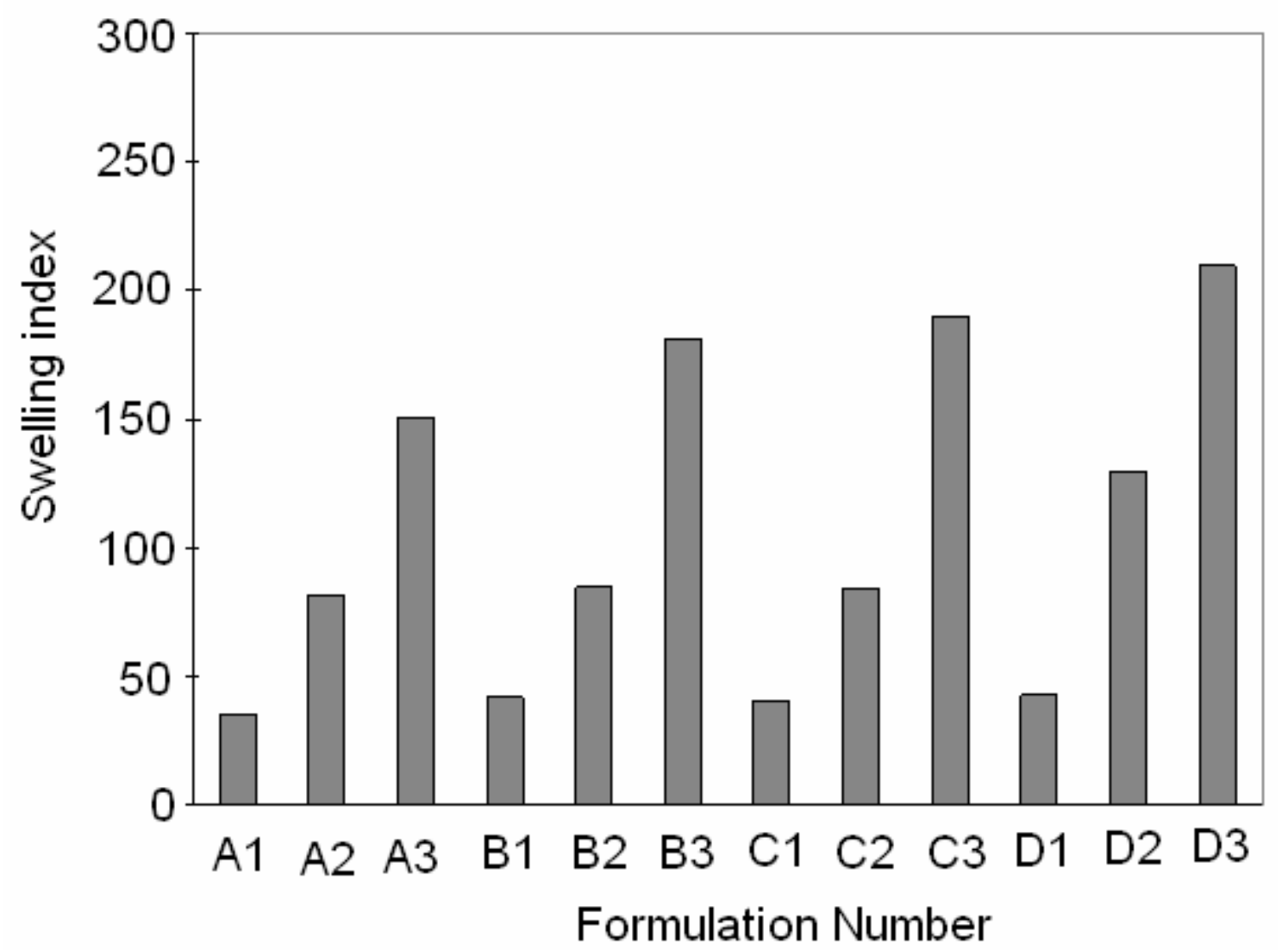

Figure 5: Influence of varying ph on swelling index of swellable MR isoniazid tablets 


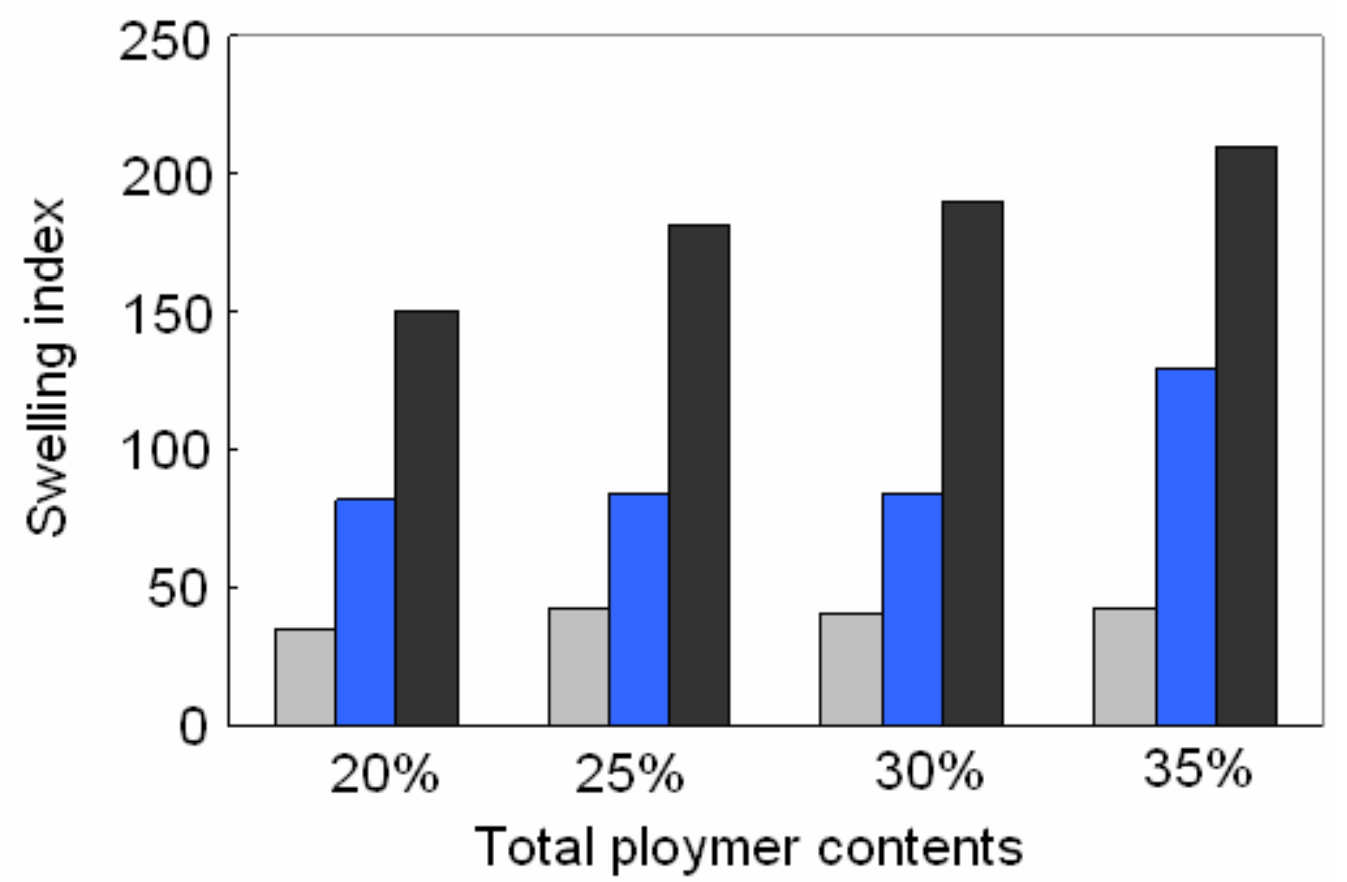

Figure 6: Influence of total polymer content on swelling index of swellable MR isoniazid tablets at varying $\mathrm{pH}(\mathrm{Grey}=8: 2$, Blue $=5: 5$ and Black $=2: 8$ )

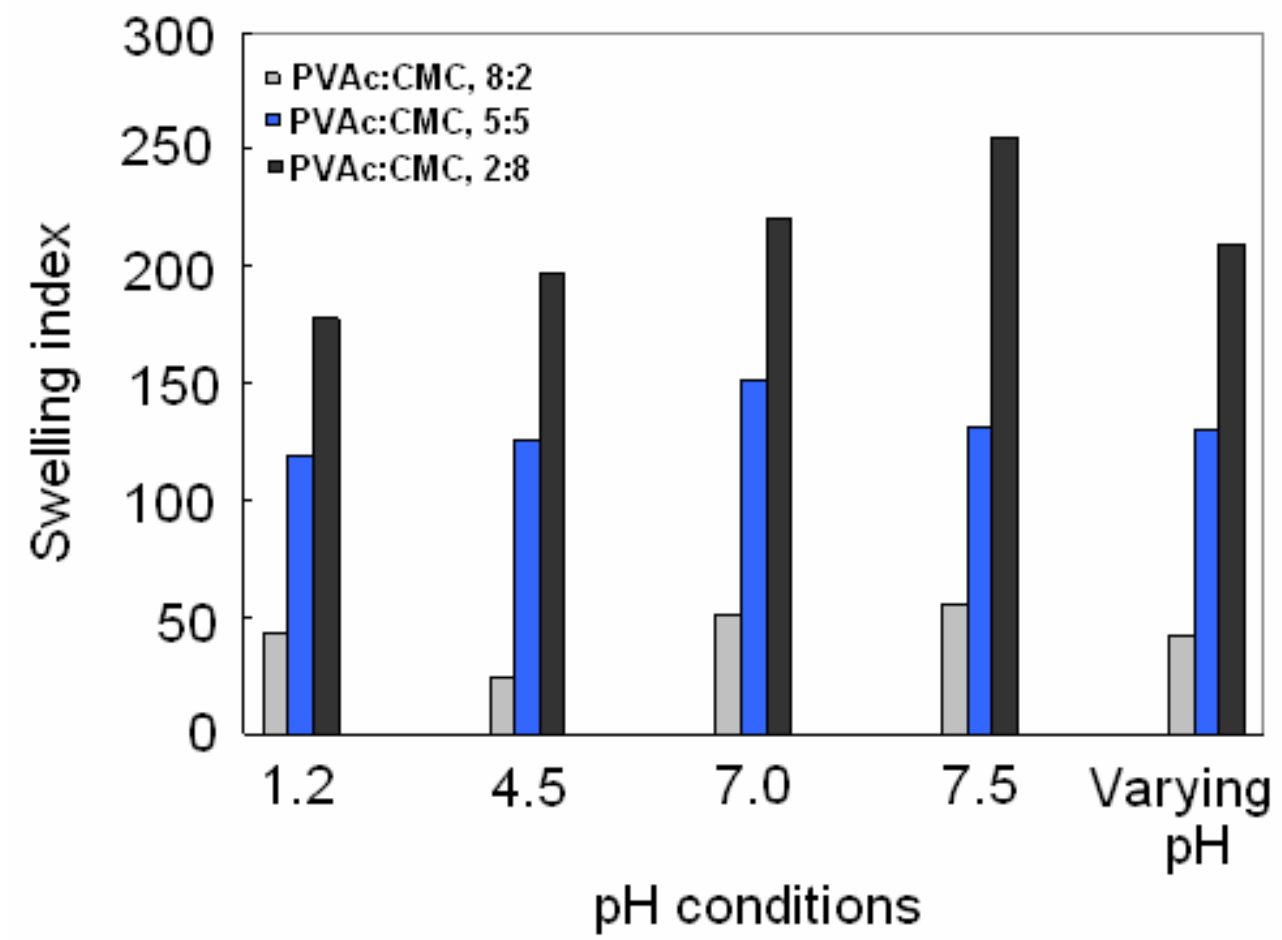

Figure 7: Influence of PVAc and NA-CMC ratio on swelling index of swellable MR isoniazid tablets in different $\mathrm{pH}$ environments

When total polymer content of $30 \%$ of the tablet weight was evaluated for drug release at three levels i.e. polymer ratios of 80:20, 50:50 and 20:80 of PVAc and $\mathrm{Na}-\mathrm{CMC}$ in the form of $\mathrm{C} 1, \mathrm{C} 2$ and $\mathrm{C} 3$, then $\mathrm{C} 1$ and $\mathrm{C} 2$ released 100\% drug only in 10 hours whereas C3 released $100 \%$ drug in 11 hours. Only C1 showed initial burst release. MDT values of C1, C2 and $\mathrm{C} 3$ were found to be 3.21, 3.77 and 3.50 hours, which showed that $\mathrm{C} 2$ had more release retarding efficacy. Release profiles are expressed in Figure 3. This initial burst release, in the case of $\mathrm{C} 1 \mathrm{might}$ be attributed to higher level of PVAc which could not retard release of drug at low presence of Na-CMC. C2 did not show such burst release probably due to 
enough amount of $\mathrm{Na}-\mathrm{CMC}$ which failed to swell at low. Also its swelling at higher $\mathrm{pH}$ values could not affect any significant drug release with increasing $\mathrm{pH}$ conditions. $\mathrm{C} 3$ also did not show such burst release which may be due to higher ratio of $\mathrm{CMC}$ which formed gel and thus retarded drug release more than $\mathrm{C} 1$. PVAc was present in higher amounts in $\mathrm{C} 1$ than in $\mathrm{C} 2$ and $\mathrm{C} 3$, which caused initial burst release due to high swelling at lower $\mathrm{pH}$. Other contributing factor for initial high release was slightly basic nature of isoniazid which dissolved more readily in acidic media, but this factor is less important value owing to highly soluble nature of isoniazid in water. In the case of $\mathrm{C} 3, \mathrm{Na}-\mathrm{CMC}$ swelled more with the increase in $\mathrm{pH}$ leading to increase in drug release from dosage form when dissolution media was changed to less acidic and later on basic $\mathrm{pH}$ conditions.

When total polymer content of $35 \%$ of the tablet weight is evaluated for drug release at three levels i.e. polymer ratios of 80:20, 50:50 and 20:80 of PVAc and Na-CMC in the form of D1, D2 and D3, then 100\% drug was released in D1 in 10 hours, in 12 hours in D3 where as in D2, 93.20\% drug released in 12 hours. MDT values of D1, D2 and D3 were found to be 3.36, 4.08 and 3.88 hours, which showed that D2 had more release retarding efficacy. . Release profiles are expressed in Figure 4. The initial high release, in the case of D1 might be attributed to higher level of PVAc which could not retard release of drug at low presence of Na-CMC. D2 and D3 did not show such high initial release which may be due to higher ratio of $\mathrm{Na}-\mathrm{CMC}$ which formed gel and thus retarded drug release more than D1 and D2. PVAc was present in higher amounts in D1 than in D2 and D3, which caused initial burst release due to high swelling at lower pH. Other contributing factor for initial high release was slightly basic nature of isoniazid which dissolved more readily in acidic media, but this factor is less important value owing to highly soluble nature of isoniazid in water.

Tablets of D3 latter on, after about 4 hours, started to rotate with the dissolution media and ascended up to $3 / 4$ part of the dissolution flask. As compared to D2, it therefore allowed higher amount of drug to be released latter on, it might be due to the separation of gel formed around its surface which would otherwise retard the drug release from the tablets. The other factor for higher release from D3 than D2 was that the tablets of D3 swelled quite more than those of D2 allowing more drug to be released from D3.

For water soluble slightly basic drugs such as isoniazid, overall effect of increasing total polymer content was increase in total dissolution time for 100 percent release of the drug from tablets as has been previously investigated for Kollidon SR (Reza et al. 2003). Overall effect of increasing polymer content, with PVAc and Na-CMC used in the ratio of $80: 20$, resulted in increasing total dissolution times for 100\% release of the drug from the tablet and increased MDT but failed to minimize initial burst release due to higher ratio of PVAc to Na-CMC. Same results of varying polymer concentration at PVAc to Na-CMC ratio of 50:50 were obtained. The PVAc to CMC ratio of 20:80 also behaved similarly. Formulation number $\mathrm{C} 3$ released more percentage of the drug due to higher swelling of CMC at high concentration during early time of basic medium and started rotating and suspended in dissolution media which led to removal of gel layer on the tablet surfaces. This suspension and rotation of tablets might have occurred due to tablet's lower density than water resulting from higher swelling of Na-CMC. Thus, this type of combination of Na-CMC and PVAc can be used in the formulation of floating tablet formulation as it had been previously used along with HPMC to formulate floating tablets (Narendra et al. 2006). The D3 also started to rotate and suspended in dissolution media, but did not give higher release than $\mathrm{C} 3$. It occurred due higher polymer concentration present in the formulation which resulted in more release retarding effect.

The in vitro modified release of Isoniazid from the tablets prepared using PVAc and Na-CMC were examined by performing dissolution tests under the following conditions. Conditions of dissolution tests: paddle method, $\mathrm{pH}$ 1.2, 4.5, 7.0, 7.5 , dissolution medium volume $1000 \mathrm{ml}$. and then different mathematical models were applied to analyze dissolution profiles. Isoniazid gave initial burst release in all the formulations due to its higher solubility in acidic media because of its high $\mathrm{pKa}(\mathrm{pKa}=7.5)$ and also due to swelling of the polymers in the tablets which allowed more water to come into contact with the drug. This initial burst release was more prominent in those formulations which contained PVAc and Na-CMC in the ratio of 8:2 which was might be due to less gel formation by the combination containing less amount of Na-CMC which otherwise retarded the drug release when present in high amount even in the presence of higher swelling ratios, this gelling effect of Na-CMC has been previously investigated with HPMC (Narendra et al. 2006).).

The Higuchi model best explained the drug release data, according to which drug release is directly proportional to the square root of time, as its value of $\mathrm{R}^{2}$ was greater than 0.9135 for all formulations. Analysis of the dissolution profiles by the Hixson-Crowell model elaborated a change in surface area and diameter of the formulations with progressive dissolution of the matrix as a function of time. Anomalous diffusion was the mechanism of drug release from microparticles. According to the Korsmeyer-Peppas model, the value of " $\mathrm{n}$ " from 0.45 to 0.89 indicates the anomalous diffusion (Murtaza et al. 2009). The swelling and erosion of the matrix is likely to be responsible for such type of drug release from tablet matrix. The anomalous diffusion shows that drug transport is mainly governed by coupling of Fickian diffusion of the drug from the tablets and polymer relaxation and swelling. Polymer chain relaxation suggested as one of the main drug transport is the swelling of the polymer chain molecules which latter on causes the polymer chains to become mobile leading the polymer chains to form three fronts, one moving front at which swelling is taking place, it is called as swelling front and the other diffusion front which separates the un-dissolved drug from swelling front. The third front is the erosion front which separates the dosage form from dissolution medium (Siepmann and Siepmann, 2008).

This value of $n$ suggests that polymer relaxation and swelling of the tablets are the primary causes involved in the release of water soluble drugs and not the erosion of the polymers because if it would be the cause of release then $n$ value would show super case transport. This finding in that study is in conformity to the previous work which suggests that water soluble drugs are released due to swelling and not because of erosion (Reza et al. 2003). The results of this mathematical analysis applied to all formulations of MR swellable isoniazid tablets are summarized in the table number 5. Although release rate constant $\mathrm{K}$ is the measure of drug release but it should not be used to characterize drug release due to the differences in drug release kinetics. Since MDT shows the drug release retarding efficacy of the polymers used in a formulation, there fore it was used for comparison of release profiles of different formulations. MDT was calculated to characterize drug release from dissolution data and to compare drug release in different formulations. For calculation of MDT, value of K and $\mathrm{n}$ were 
calculated according Korsmeyer-Peppas equation. Mean Dissolution Time (MDT) was calculated from the following equation according to Mockel and Lippold (Mockel and Lippold, 1993).

$$
\text { MDT }=[\mathbf{n} /(\mathbf{n}+1)] \times \mathbf{K}^{-1 / n}
$$

Here $\mathrm{K}$ is the kinetic constant and $\mathrm{n}$ is the release exponent calculated from Korsmeyer-Peppas equation, Mt $/ \mathrm{M} \infty=\mathrm{K} . \mathrm{t}^{\mathrm{n}}$. As the value of MDT increased with increasing total polymer content at specific ratios of polymers, it shows that increasing polymer content at all the three ratios of PVAc and CMC investigated in this study led to increase in MDT. So increase in polymer loading led to increased release retarding capability which was apparent from the higher MDT i.e. higher the polymer concentration, higher the MDT irrespective of the ratios of the polymers This finding is in accordance to the previous finding (Reza et al. 2003).

In this study, it was found that as the polymer ratio changed while total polymer content remained constant, then values of MDT changed which showed their relative drug release retarding efficacies at a specific concentration. Table 5 represents the values of MDT calculated for all the formulations along with their respective $\mathrm{n}$ and $\mathrm{K}$ values.

Variation in $\mathrm{pH}$ conditions significantly affected swelling of PVAc and $\mathrm{Na}-\mathrm{CMC}$ based isoniazid tablets at all $\mathrm{pH}$ conditions, except the effect of $\mathrm{pH} 1.2$, which caused least swelling for formulations $\mathrm{A}_{1}, \mathrm{~B}_{1}, \mathrm{C}_{1}$ and $\mathrm{D}_{1}$ which had higher contents of PVAc but other formulations showed higher swelling which was due to higher Na-CMC levels.

Overall effect was that at $\mathrm{pH} 7.5$ most of the formulations showed highest swelling. When varying pH condition was used to analyze swelling, then at higher $\mathrm{pH}$ levels, tablets showed continuous swelling, as soon as $\mathrm{pH}$ was increased, swelling index (S.I.) increased until most of the Na-CMC dissolved and tablet eroded. Figure 5 summarizes the effect of varying pH on S.I. of all the formulations.

When the total polymer content was increased, then all the formulations showed higher swelling at all $\mathrm{pH}$ conditions. Also their increase resulted in prolongation of swelling effect. It occurred so because PVAc swells more at acidic $\mathrm{pH}$ where as $\mathrm{Na}-\mathrm{CMC}$ swells more at higher $\mathrm{pH}$, such a trend is shown from the figures of S.I. of all the formulations, from them it is apparent that all the formulations showed higher S.I. in Dynamically changing $\mathrm{pH}$ than at acidic $\mathrm{pH}$. At $\mathrm{pH} 4.5,7.0$ and 7.5, S.I. of each formulation was higher than the acidic $\mathrm{pH} 1.2$. It shows that tablets of PVAc swells less at higher $\mathrm{pH}$ conditions where as tablets of $\mathrm{Na}-\mathrm{CMC}$ swells more at higher $\mathrm{pH}$ conditions but also swells at acidic pH. Figure 6 summarizes the effect of polymer content on S.I. of all the formulations.

Formulations with same total polymer content but with PVAc to Na-CMC ratio 80:20 showed lower S.I. than those of PVAc to Na-CMC ratio of 50:50 and 20:80. This means that when Na-CMC to PVAc ratio was increased, then the tablets showed higher swelling Index. Increasing ratio of $\mathrm{Na}-\mathrm{CMC}$ in the formulations resulted in increasing S.I. and more gel formation which is in similarity to the previous finding in which Na-CMC was used in combination with HPMC (Efentakis et al. 1997). Figure 7 shows that Na-CMC increased Swelling Index of the tablets in every pH environment studied when PVAc was replaced by Na-CMC in formulations. So it can be assumed from this finding that in the case of PVAc and NaCMC based isoniazid tablets, amount of Na-CMC significantly affects swelling index as compared to PVAc. Figure 7 summarizes the effect of polymer ratios on S.I. of all the formulations.

\section{Conclusion}

On the basis of this study, it is concluded that a model of sustained zero order release formulation with initial high release and later slow release to sustain drug plasma concentration can be successfully implemented on the swellable modified release isoniazid tablets.

\section{References}

1. Hara, P. O. and Hickey, A. J. (2002). Respirable PLA microspheres containing rifampicin for the treatment of tuberculosis: Manufacture and characterization. Pharm. Res., 17: 955-961.

2. Blomberg, B.; Spinac, S.; Fourie, B. and Laing, R. (2001). The rationale for recommending fixed dose combination tablets for treatment of tuberculosis. Bull. World Health Org., 79: 348-354.

3. Mariappan, T. T. and Singh, S. (2003). Regional gastrointestinal permeability of rifampicin and isoniozid (alone and their combination) in the rat. Int. J. Tuberc. Lung Dis; 7: $797-803$.

4. Reza, M. S.; Abdul-Quadir, M. and Haider, S. S. (2003). Comparative evaluation of plastic, hydrophobic and hydrophilic polymers as matrices for controlled-release drug delivery, J Pharm Pharm. Sci; 6,282-291.

5. British Pharmacopoeia (2004). Appendix XII G. Uniformity of Weight (Mass). London: British Pharmacopoeia Commission. P 1.

6. USP30-NF25. (2007). The Official Compendium of Standards. The United States Pharmacopoeial Convention, 1 May 2007.

7. Murtaza, G.; Ahamd, M.; Akhtar, N. and Rasool, F. (2009). A comparative study of various microencapsulation techniques: Effect of polymer viscosity on microcapsule characteristics. Pak. J. Pharm. Sci., 22: 291-300.

8. Davidson, A. G. (2002). In Practical pharmaceutical chemistry (Ed Beckett, A. H. Stenlake, J. B.) $4^{\text {th }}$ Edition, CBS Publishers, p 275-337.

9. Narendra, C.; Srinath, M. S. and Babu, G. (2006). Optimization of Bilayer Floating Tablet Containing Metoprolol Tartrate as a Model Drug for Gastric Retention. AAPS Pharm. Sci. Tech; 34: E1-E7.

10. Siepmann, J. and Siepmann, A. (2008). Review on Mathematical modeling of drug delivery. Int. J. Pharmaceutics; 364: 328-343.

11. Mockel, J. E. and Lippold, B. C. (1993). Zero order release from hydrocolloid matrices. Pharm. Res; 10: 1066-1070.

12. Efentakis, M.; Vlachou, M. and Choulis, N. H. (1997). Effects of Excipients on Swelling and drug release from compressedMatrices. Drug Dev. Ind. Pharm; 23: 107-1 12. 